\title{
GNSS-based operational monitoring devices for forest logging operation chains
}

\author{
Raimondo Gallo, ${ }^{1}$ Stefano Grigolato, ${ }^{2}$ Raffaele Cavalli, ${ }^{2}$ Fabrizio Mazzetto ${ }^{1}$ \\ Free University of Bozen-Bolzano, Faculty of Science and Technology, Bolzano, Italy; \\ Forest Operation Management Unit, ${ }^{2}$ Dept. Land, Environment, Agriculture and Forestry, \\ University of Padova, Italy
}

\begin{abstract}
The first results of a new approach for implementing operational monitoring tool to control the performance of forest mechanisation chains are proposed and discussed. The solution is based on Global Navigation Satellite System (GNSS) tools that are the core of a datalogging system that, in combination with a specific inference-engine, is able to analyse process times, work distances, forward speeds, vehicle tracking and number of working cycles in forest operations. As a consequence the operational monitoring control methods could provide an evaluation of the efficiency of the investigated forest operations.The study has monitored the performance of a tower yarder with crane and processor-head, during logging operations. The field surveys consisted on the installation of the GNSS device directly on the forest equipment for monitoring its movements. Simultaneously the field survey considered the integration of the GNSS information with a time study of work elements based on the continuous time methods supported by a time study board. Additionally, where possible, the onboard computer of the forest machine was also used in order to obtain additional information to be integrated to the GNSS data and the time study. All the recorded GNSS data integrated with the work elements study were thus post-processed through GIS analysis.

The preliminary overview about the application of this approach on harvesting operations has permitted to assess a good feasibility of the use of GNSS in the relief of operative times in high mechanised forest chains. Results showed an easy and complete identification of the different operative cycles and elementary operations phases, with a maximum difference between the two methodologies of $10.32 \%$. The use of GNSS installed on forest equipment, integrated with the inference-
\end{abstract}

Correspondence: Raimondo Gallo, Free University of Bozen-Bolzano Faculty of Science and Technology Piazza Universitá 5, 39100 Bolzano BZ Italy.

Email: raimondo.gallo@natec.unibz.it

Key words: precision forestry, forest operation performance, operationalmonitoring, time study.

(C) Copyright R. Gallo et al., 2013

Licensee PAGEPress, Italy

Journal of Agricultural Engineering 2013; XLIV(s2):e27

doi:10.4081/jae.2013.s2.e27

This article is distributed under the terms of the Creative Commons Attribution Noncommercial License (by-nc 3.0) which permits any noncommercial use, distribution, and reproduction in any medium, provided the original author(s) and source are credited. engine and also with an interface for data communication or data storage, will permit an automatic or semi-automatic operational monitoring, improving the quantity of data and reducing the engagement of the surveyor.

\section{Introduction}

As in agriculture, also in the forest sector the information technology has been introduced with the aim to improve the efficiency and performance of this sector. Indeed the Precision Forestry is the approach that employs the well known strategies and methodology of Precision Agriculture and Precision Farming to the forest sector in order to obtain a decision support system (DSS) (Lubello et al., 2006). The Precision Forestry, starting from the well-established Precision Agriculture, presents some research topics not yet completely explored. One of these is the study of operational monitoring in automatic ways. Considering the equipment on which the Precision Forestry bases its applications, the Global Navigation Satellite System (GNSS) device is one of the most important.

The aim of this study is to detect the operative times through the use of a GNSS device that, at each fixing point, is able to perform also a time acquisition. The operational time study is considered as "a set of procedures for determining the amount of time required, under certain standard conditions of measurement, for tasks involving some human, machine, or combined activities" (Mundel and Danner, 1994). At this regard, the operational time study became an important parameter for the assessment of the productivity. Indeed, thanks to the time survey, it is possible to evaluate which is the efficiency of the entire work systems (machineries and humans activities), the singular equipment or the team of workers.

The analysis of the operational times or time consumption measurement, in forestry sector is usually done thanks to the use of time study boards or hand held computers or by automated data collectors attached to forest machines' computers and CAN-bus channels (Nuutinen et al. 2010). Automatic operational time study based on the installation of GNSS on machineries that operate in forest are also quite common. This methodology is mainly applied for the tracking of the movements of the machineries for felling and skidding operations in forest (Taylor et al., 2006; Cordero R., et al., 2005; McDonald and Fulton 2005, McDonald et al., 2001, Taylor, et al., 2001; Veal, et al., 2001; McDonald 1999) and for tracking the trucks for timber haulage (Simwanda et al., 2011; Devlin and McDonnell, 2009; Devlin et al., 2008; Sikanen et al., 2005). Only a document on the use of GPS for the analysis of tower yarder was found (Nitami et al., 2011).

The aim of this study is to verify the feasibility to develop a methodology for acquisition, elaboration and interpretation of the data autonomously. The methodology must recognizes and reliefs the num- 
ber of cycles of work, each elementary phase and also the respective operational time. This will be possible thanks to the development of an inference-engine able to transform satellite raw data into intelligible management information (Mazzetto et al., 2012). The operational time data acquisition system was then validated through the comparison with an operational monitoring relief with stopwatch. This paper presents the preliminary results and discussions.

\section{Materials and Methods}

\section{Study area}

The study-case was set during the logging operations of conversion of a secondary forest of Norway spruce (Picea abies L.) in a mixed forest mainly composed of beech (Fagus sylvatica L.). The forest yard, interested by the cultural operation, was organized in pre-alpine region, in the N-E of Italy (Pordenone Province - Friuli Venezia Giulia Region). The machineries that compose the mechanisation chain were chains saw and Mayr-Melnhof®-MM Syncrofalke, mobile tower yarder with crane and processor-head. The employed carriage was a MM Sherpa with $3 \mathrm{t}$ payload.

The data-logger used for the automatic reliefs was a Geographical Position System (GPS) mobile device installed on the cable yarder's carriage. The GPS unit is an ASCTECH® MobileMapper 6, a 12-channel singular frequency device; which runs Windows Mobile 6, and the specific software MobileMapper Field on a $400 \mathrm{MHz}$ cpu. In order to assure a better reception of the satellite's signals, an external antenna was connected. In order to protect the GPS from any accidental shocks, a plastic box with layers of foam was built. Finally the box, which carried the GPS, was fixed to the internal body of the carriage (Figure 1a) with plastic ties. Meanwhile the external antenna was placed on top of the frame by means of a magnet. The antenna connection cable was fixed to the lateral frame of the carriage with scotch tape in order to avoid any entanglement with branches (Figure 1b).

The GNSS device was set with an automatic data acquisition of the carriage's position every 3 seconds.

A time study board with three decimal stopwatches was used for the manual relief of operative times necessary to the validation of the data. The manual time relief was based on the continuous time methods. The methodology requires the presence of two surveyors: one placed in the felling point and the other one placed on the temporary storage area for the relief of possible operative down-time during the downloading operations as well as the relief of timber's volumes exploited. The communication between the surveyors was supported by radio. The operational monitoring was based on the identification of elementary operations for operative times as following:

- Travel empty: when the carriage starts movement from the unhooking site (landing) to when it stops along the line for starting the hooking phase;

- Hooking: from when the carriage stops to when the log movements start;

- Side-lining: from the start of the log movements to the unlock of the carriage;

- Load travel: from the unlock of the carriage to the next lock in proximity of the tower yarder for the unhooking;

- Unhooking: from the lock of the carriage and start of the download operation to the unlock for the start of the next cycle;

Meanwhile, the operative down-times were identified due to: mechanical reasons (in the case of machine break-down), operative reasons (delay because the operator is interested in more than one activity), operator's personal reasons (personal needs) or study reasons.

\section{Elaboration data}

Data acquisition that, set with a period of collection of 3 seconds of interval, was post-processed through the use of the software MobileMapper Office 4.0. The elaboration returned correct coordinates, altitude as well as recording time. Using these data following values of instantaneous speeds, movements, advancement direction were obtained. Since the system must work without any reference data , and also reduce the influence of possible low accuracy of the data, a methodology to establish an initial reference point $\mathrm{P}_{\mathrm{r}}\left(\mathrm{x}_{\mathrm{r}} ; \mathrm{y}_{\mathrm{r}}\right)$ - external to the points cloud in proximity of the starting point - was necessary (Figure 2).

The determination of $\mathrm{P}_{\mathrm{r}}$ is done in order to obtain a starting point as reference for the detection of all distances of the entire points of the data-set. The first point collected by GNSS device identifies the start of the relief, then, the recognition of the logging direction establishes the choice of the coordinates for $\mathrm{P}_{\mathrm{r}}$. The attribution is done considering the maximum or minimum coordinates of the points of the cloud in the proximity of the initial point. When the referencing point of the system is detected, the distances from $\mathrm{P}_{\mathrm{r}}$ of the entire set of points were calculated in order to have a common variable to analyse the relationship between variables.
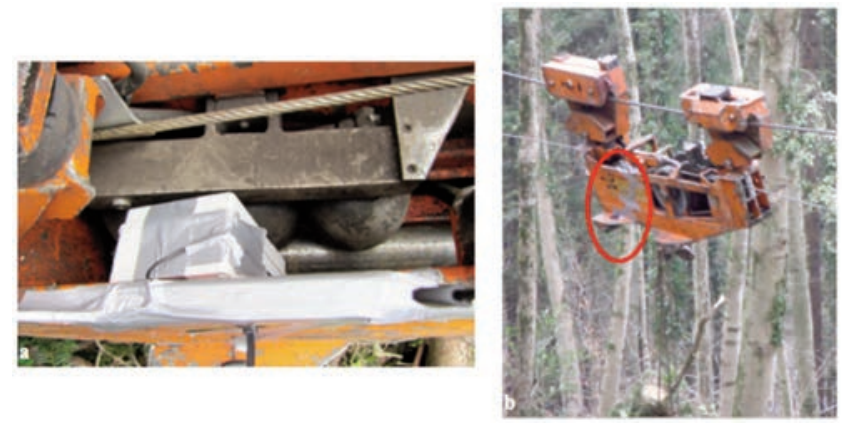

Figure 1. Installation of GNSS device on carriage (a: particular view; b: during detecting operations).

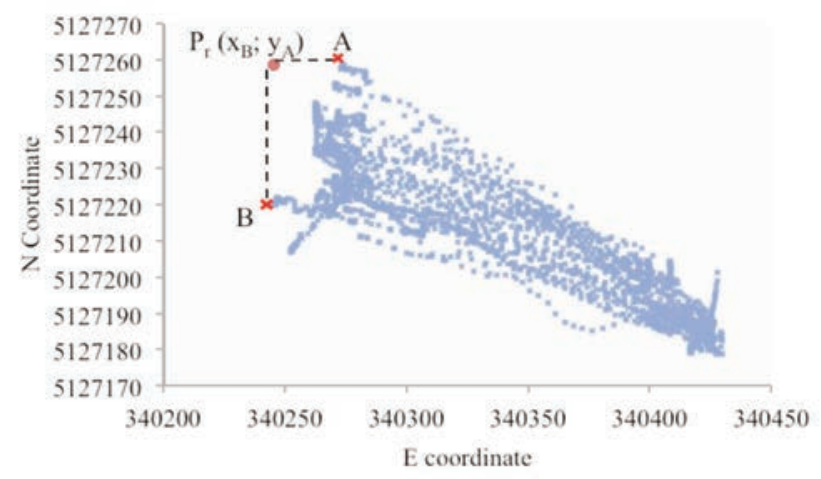

Figure 2. Distribution of GPS detections and identification of the point of reference $P_{r}$ recognising $A$ and $B$ as the extreme point of the cloud and $\mathrm{N}-\mathrm{E}$ as logging direction. 


\section{Results and Discussions}

During this study case a total of 2 days of automatic and manual monitoring were done. Only the data collected during the second day were usable for the elaborations. Due to the low precision and accuracy of the first day's acquisitions it was not possible to perform the postprocessing elaboration of the raw data. Therefore only one data-set was post-processed and elaborated; it is represented in Figure 2. The relief consists in an effective survey of 3.6 hours of work with a data-set of 3093 records. In fact the number of records is lower than what corresponds to 3.6 hours. This lack of time information occurred as empty spaces during the data acquisition and also as drift points. In fact the expected result from GPS detection should be a series of points more or less along the same line. Anyhow correlating the times gap with the respective distances of the registered position (Figure 3 ) and comparing them with the other graphs that describe the carriage's kinematic behaviour, (Figure 4; Figure 5a; Figure 5b), it was possible to detected that this phenomenon occurred mainly when the carriage is blocked for hooking or unhooking operations.

These time gaps happen rarely during the advancement. The drifting of the points could be due to several factors as: the canopy coverage (McDonald and Fulton, 2005), the loss or the acquisition of new satellite's signal (Taylor et al., 2006) - that determine a recalculation of the GNSS device position -, the insufficient satellites coverage or their geometric distribution (Naesset et al., 2000) during the acquisition data. But in this case it is possible to say that the drift is caused by multipath interference due to the closeness with steel equipment (truck and carriage frame), that bounced the satellite's signal, and also by the bad weather with fog and fine rain during the relief, which influenced the speed at which the satellite radio waves travelled (Naesset et al., 2000). For making a first description of carriage's kinematic behaviour data about distances, advancement speeds and advancement directions were necessary (Figure 4; Figure 5a; Figure 5b).

In Figure 4 the advancement direction of the carriage during its movements and during the hooking and unhooking operations is reported. Its relationship with the distances from the point of reference highlights two distinguished families of points. Each in correspondence to the average values of $110^{\circ}$ and $290^{\circ}$. These represent the direction of movement of empty and loaded travels respectively. While the carriage stops the advancement and during the hooking and unhooking operations the values of direction do not have linear distributions. This is due to the oscillation caused by the weight of the logs during the load or unloads operations. As far as the analysis of the advancement speeds is concerned, it is possible to say that the carriage travels with an advancement speed higher than $2.5 \mathrm{~m} / \mathrm{s}$ during its travel operations. It is also possible to note that the advancement speed is split in two different families of points, better visible in figure $5 \mathrm{~b}$, with different average values of speed: $2 \mathrm{~m} / \mathrm{s}$ for the lower and $3 \mathrm{~m} / \mathrm{s}$ for the higher, respectively for loaded and empty travel. Besides this, in figure $5 \mathrm{a}$ it is easy to identify also the points where the carriage blocks its advancement in correspondence to the hooking area as well as the point of automatic arrest in proximity of the tower yarder during the empty travel (red arrows in the Figure 5a).

After that, analyses of the working cycles (Figure 6) were done in order to obtain the gross cycle time and the elementary operational times. Through this elaboration it was possible to analyse the relationship between the progressive time (considered as the sum time difference between two sequent points) and the respective distance from the point of reference.

Results of the gross and elementary study time are summarized in the following tables (Table 1,2).

To facilitate the procedure of operational times recognition they are not considered at net to down-times. During the study a total of 21 cycles was monitored, the first one, being a trial run, was not considered. McDonald (2005) reported that the automatic time study with the use of GNSS device is able to correctly recognize at least $90 \%$, of the cycles, in the present study the result is better because all cycles were recognized. The very good results obtained are also demonstrated by the high value of correlation between the manual relief and the automatic ones (Figure 7). Anyhow, in total, a difference below 4 minutes was observed between the two methodologies of relief. Probably these

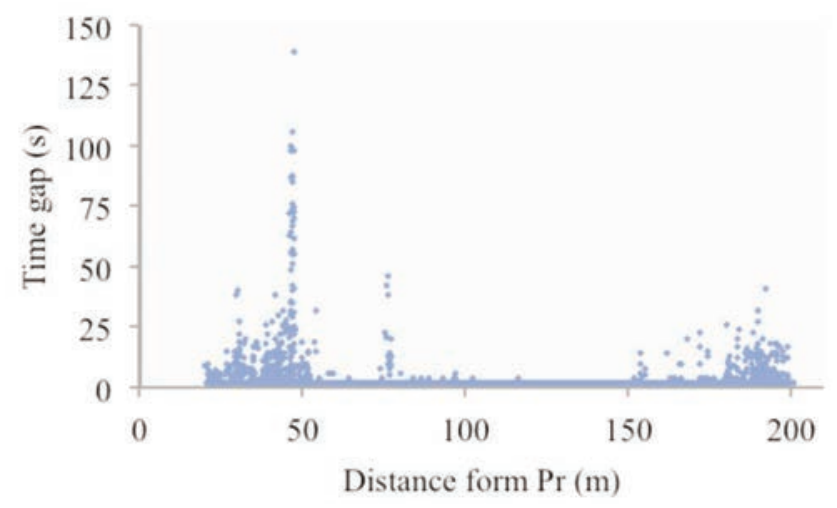

Figure 3. Times gap distribution in relation to the distance from $P_{r}$.

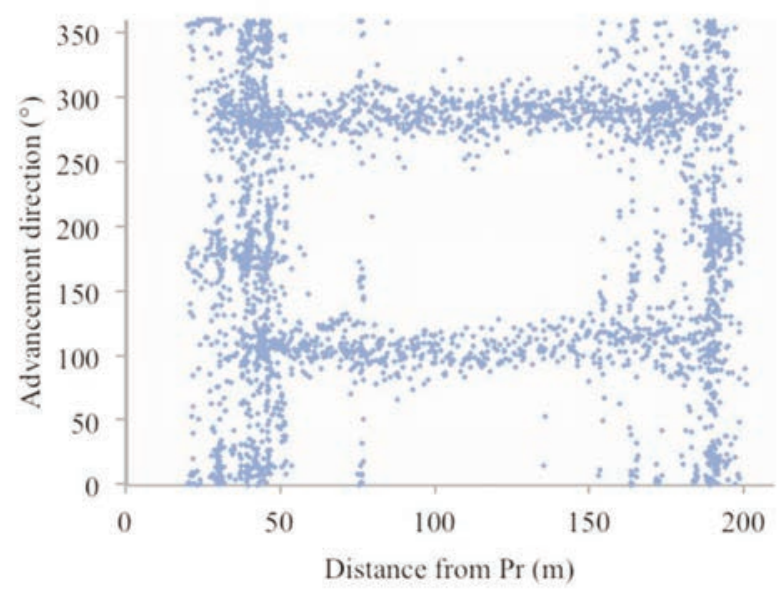

Figure 4. Distribution of the advancement directions in relation to distance from $P_{r}$.

Table 1. Number of cycles and gross operative time summary.

\begin{tabular}{lcc} 
& $\begin{array}{c}\text { Operative Cycle } \\
\text { N }\end{array}$ & $\begin{array}{c}\text { Gross operative time } \\
\text { min }\end{array}$ \\
Automatic relief GNSS (AR) & 20 & 135.12 \\
\hline Manual relief Clock (MR) & 20 & 131.51 \\
Difference & - & $-2.75[\%]$ \\
\hline
\end{tabular}


are due to recording discontinuities during time detections, and to the presence of communications delays between the two surveyors due to transmission troubles of the walkie-talkie. Meanwhile for what concerns the elementary time study, the side-lining operations were not identifiable, because the detected parameters were not sufficient for that. So, in order to proceed with the analysis, hooking and side-lining operations were considered together. Also in this case all operative phases were recognized. For the elementary phases, substantial time differences between the GNSS and clock detections were found (Figure 7). These are mainly present during travels. Explanation of that could be associated to the difficulties during the determination of the shift values between sequent phases (Table 2 ).

Table 2. Operative time summary for each elementary phase.

\begin{tabular}{|c|c|c|c|c|c|c|c|c|}
\hline \multirow[t]{2}{*}{ Operative cycle } & \multicolumn{2}{|c|}{ Empty travel } & \multicolumn{2}{|c|}{ Hooking } & \multicolumn{2}{|c|}{ Loaded travel } & \multicolumn{2}{|c|}{ Unhooking } \\
\hline & $\begin{array}{c}\text { GNSS } \\
\text { min }\end{array}$ & $\begin{array}{l}\text { Clock } \\
\text { min }\end{array}$ & $\begin{array}{c}\text { GNSS } \\
\text { min }\end{array}$ & $\begin{array}{c}\text { Clock } \\
\text { min }\end{array}$ & GNSS & Clock & GNSS & Clock \\
\hline 1 & 0.80 & 0.85 & 0.63 & 0.52 & 1.57 & 1.52 & 1.68 & 1.77 \\
\hline 2 & 1.12 & 0.71 & 1.60 & 1.45 & 1.47 & 1.37 & 1.33 & 1.47 \\
\hline 3 & 0.97 & 0.81 & 1.72 & 1.82 & 2.55 & 1.91 & 3.78 & 3.33 \\
\hline 4 & 1.08 & 0.92 & 1.60 & 1.64 & 1.87 & 1.75 & 1.00 & 1.08 \\
\hline 5 & 0.80 & 0.85 & 0.77 & 0.84 & 1.50 & 1.44 & 2.97 & 3.00 \\
\hline 6 & 0.90 & 0.65 & 1.00 & 1.17 & 2.73 & 2.45 & 1.17 & 1.52 \\
\hline 7 & 0.97 & 0.92 & 1.23 & 1.44 & 2.85 & 2.75 & 0.48 & 0.47 \\
\hline 8 & 1.15 & 1.06 & 1.95 & 1.86 & 3.53 & 3.61 & 0.97 & 0.93 \\
\hline 9 & 1.07 & 1.09 & 3.80 & 3.83 & 1.67 & 1.70 & 3.00 & 3.00 \\
\hline
\end{tabular}
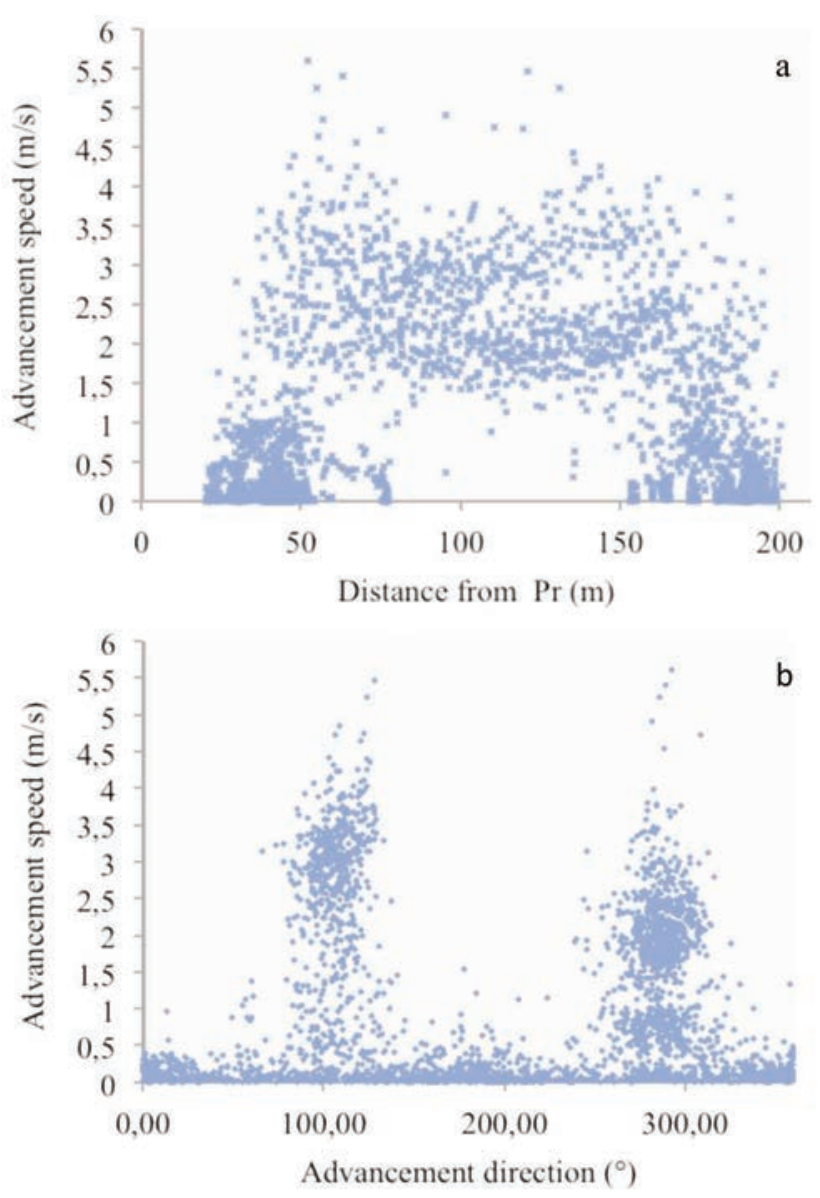

Figure 5. a) distribution of the advancement speeds in relation to distance from $\left.P_{r} ; b\right)$ distribution of the advancement speeds in relation to advancement directions.

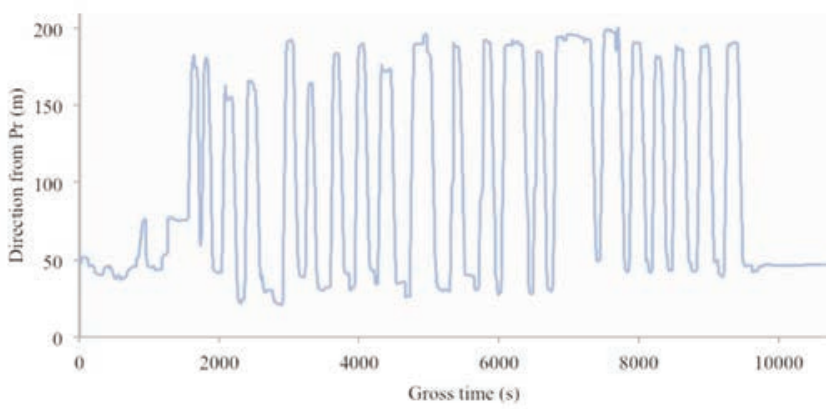

Figure 6. Representation of the entire cycling work.

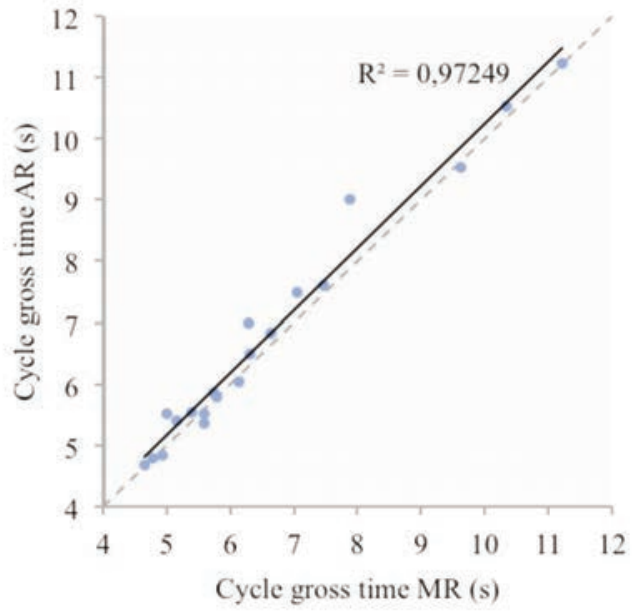

Figure 7. Correlation between manual relief (MR) and automatic relief (AR) with GNSS device. 


\section{Conclusions}

Despite the short test period, experiences obtained very interesting and important results for further improvement of the assess methodology. This initial part of the research has shown that the use of GNSS devices presents a very interesting feasibility for performing operational time monitoring in forest logging operations. All operative cycles and all elementary operations have been exhaustively recognized. Considering the cycle's gross times the differences are lower than $2.75 \%$, corresponding to 3.61 minutes. Meanwhile the differences between the elementary operations are higher. Indeed the two methodologies present a maximum difference of $9.24 \%$, which means a maximum average error lower than $0.46 \%$ ( 0.18 minutes) for each cycle. This value could be considered acceptable. In order to increase the accuracy of the automatic time relief it could possible employ GNSS devices those reach signal from both satellite constellation: GPS and GLONASS.

From these first results several open points were found, next steps of the research will be the identifications of the reasons of the drifting phenomena during the GNSS detection and also of the discrepancy between the times relieved mainly during travel operations. Besides this, new strategies for the detection of side-lining operations will be analysed. The possibility of including further sensors (such as load cells for measuring the weight of timbers hooked to the crane) will be considered as well, in order to provide more information for a better performance of the inference-engine.

\section{References}

Cordero R., Mardones 0., and Marticorena M. 2006. Evaluation of forestry machinery performance in harvesting operations using GPS technology. In: Precision Forestry in Plantations, Semi-Natural and Natural Forests, Proceedings of the International Precision Forestry Symposium, Stellenbosch University, South Africa. pp 16373

Devlin G.J., McDonnell K. 2009. Assessing Real Time GPS Asset Tracking for Timber Haulage. Open Transportation Journal 3: 7886.

Devlin G. J., McDonnell K., Ward S. 2008. Timber haulage routing in Ireland: an analysis using GIS and GPS. Journal of Transport Geography 16(1): 63-72.

Lubello D., Cavalli R. 2006. Ambiti applicative della Precision Forestry. Sherwood Foreste 125: 11-16.

Mazzetto F., Sacco P., Calcante A. 2012. Algorithms for the interpreta- tion of continuous measurement of the slurry level in storage tanks. Journal of Agricultural Engineering 43(1), e6.

McDonald T. 1999. Time Study of Harvesting Equipment Using GPSDerived Positional Data. Notes. http://treesearch.fs.fed.us/ pubs/1411

McDonald T., Fulton J. 2005. Automated time study of skidders using global positioning system data. Computers and electronics in agriculture 48(1): 19-37.

McDonald T., Rummer B., Taylor S. 2001. "Automating time study of feller-bunchers." In Proceedings of the Canadian Woodlands Forum's 81st Annual Meeting and Council on Forest Engineering's 23rd Annual Meeting- Technologies for New Millennium Forestry, Kelowna, BC.

Mundel M., Danner D. 1994. Motion and time study - improving productivity. 7th ed. Prentice Hall, Upper Saddle River, NJ. 770pp.

Nitami T., Soil S., Kataoka A., Mitsuyama T. 2010. Tower Yarder operation in Japan and the performance analysis by GPS-based system. In: Pushing the boundaries with research and innovation in forest engineering. FORMEC 2011, Proceedings of the 44th International Symposium on Forestry Mechanisation, 9-13 October 2011. Graz, Austria.

Naesset E., Bjerke T., Bvstedal 0., Ryan L. H. 2000. Contributions of differential GPS and GLONASS observations to point accuracy under forest canopies. Photogrammetric Engineering \& Remote Sensing 66(4). pp 403-07.

Nuutinen Y., Väätäinen K., Asikainen A., Prinz R. \& Heinonen J. 2010. Operational efficiency and damage to sawlogs by feed rollers of the harvester head. Silva Fennica, 44. pp 121-39.

Sikanen L., Asikainen A., Lehikoinen M. 2005. Transport control of forest fuels by fleet manager, mobile terminals and GPS. Biomass and Bioenergy 28(2). pp 183-91.

Simwanda M., Wing M. G., Sessions J. 2011. Evaluating Global Positioning System Accuracy for Forest Biomass Transportation Tracking within Varying Forest Canopy. Western Journal of Applied Forestry 26(4). pp 165-73.

Taylor S. E., McDonald T., Veal M. W., Grift T. E. 2001. Using GPS to evaluate productivity and performance of forest machine systems. In Proceedings of the First International Precision Forestry Cooperative Symposium: University of Washington, College of Forest Resource. pp 151-55.

Taylor S., McDonald T., Fulton J., Shaw J., Corley F., Brodbeck C. 2006. Precision forestry in the southeast US. In Proceedings of the 1st International Precision Forestry Symposium. pp. 397-14.

Veal M., Taylor S., McDonald T., McLemore D., Dunn M. 2001. Accuracy of tracking forest machines with GPS. Transactions of the ASAE 44(6). pp 1903-11. 